\title{
Festlegung Warum ich in diesem Körper?
}

$\mathrm{M}$

eine ersten Lebensjahre teilte ich das Zimmer mit meiner Zwillingsschwester Petra. Wir verstanden uns zwar nicht gut, aber dennoch lösten wir gemeinsam eine Reihe von Welträtseln. So brachten wir durch Experiment und gewissenhafte Wiederholungen heraus, dass, wenn einer die Augen schließt, es für den anderen nicht dunkel wird. Wir schlossen daraus, dass Tag und Nacht unabhängig von uns sind. An einem Problem aber scheiterten meine Schwester und ich gleichermaßen. Wir fragten: Warum stecke ausgerechnet ich in diesem Körper? Wir stellten die Frage unseren Eltern und erhielten keine befriedigende Antwort. Später dann, als ich Verleger für philosophische Bücher geworden war, traute ich mich manchmal, spät beim Wein, den einen oder anderen meiner Autoren mit der Frage zu behelligen. Natürlich nur solche Philosophen, die mit der Metaphysik des Geistes vertraut sind. Ich erntete stets mitleidiges Lächeln. Sofern ich überhaupt verstanden wurde, wurde mir die Frage als Scheinproblem zurückgewiesen; etwa, dass nichts Tieferes dahinter stecke als dies: Jeder Mensch hat einen Körper; und niemand kann einen anderen Körper haben als seinen eigenen. Aber zufrieden war ich nie mit den Antworten: Jeden Mitmenschen, der mir entgegentritt, kann ich ohne weiteres als Einheit von Person und Körper sehen; warum aber ist meine Innenperspektive so gänzlich anders? 